\title{
Effect of Experimental Chronic Renal Insufficiency on Bone Mineral and Collagen Maturation
}

\author{
J. E. Russell and L. V. Avioli \\ From the Department of Medicine, The Jewish Hospital of St. Louis and \\ Washington University School of Medicine, St. Louis, Missouri 63110
}

A в S T R A C T The effect of chronic renal disease on bone matrix and mineral maturation was evaluated in rats with experimental renal insufficiency of 2-11 wk duration utilizing bromoform-toluene gradient fractionation of bone powder, pulse labeling experiments with ${ }^{45} \mathrm{Ca}$ and proline- ${ }^{3} \mathrm{H}$ differential extraction, and $\mathrm{X}$-ray diffraction techniques.

Maturation defects in both collagen and mineral $\left({ }^{45} \mathrm{Ca}\right)$ metabolism were documented as early as 2 wk after the induction of uremia, when total bone calcium, inorganic phosphate, and hydroxyproline content were unchanged. The maturational defect progressed with advancing uremia despite insignificant changes in plasma $\mathrm{pH}$ and calcium, and normal bone carbonate levels.

Although circulating levels of 25-hydroxycholecalciferol were significantly lower than normal in the uremic animals, pretreatment with either this vitamin D metabolite or vitamin $\mathrm{D}_{3}$ itself failed to alter the observed changes in skeletal maturation.

\section{INTRODUCTION}

Chronic renal failure is attended by a metabolic acidosis, intestinal malabsorption of amino acids (1) and minerals, alterations in vitamin $\mathrm{D}_{3}$ metabolism as well as increased circulating levels of parathyroid hormone, and uremic toxins such as indoles and guanidines. These biological derangements either singularly or in concert result in a form of osteopenia which because of its varied histological manifestation is termed "renal osteodystrophy" (2, 3). Pellegrino and Blitz (4) and Kaye, Frueh, and Silverman (5) have reported alterations in the chemical composition and "exchangability" of bone mineral obtained from uremic subjects. Recently, Nichols et al. demonstrated that both the metabolic activity of

Dr. Russell is the recipient of a special NIH fellowship AM50025.

Received for publication 15 June 1972 and in revised form 22 August 1972. bone cells and collagen turnover are increased in virtually all patients with chronic renal insufficiency despite absence of bone disease by routine radiographic analysis (6). Preliminary observations from this laboratory have revealed an increase in the soluble, immature bone collagen pool and a decreased concentration of mature, insoluble bone collagen (7).

Clearly multiple factors are operative in chronic renal disease which contribute to the derangement in bone metabolism. Osteitis fibrosa, osteosclerosis, and osteomalacia have been well documented histologically in patients with end-stage renal failure $(8,9)$ and variably attributed to relative degrees of parathyroid hyperfunction $(10,11)$, defective renal synthesis of biologically active vitamin $\mathrm{D}_{3}$ metabolites $(12,13)$, chronic acidosis (14), and calcium malabsorption. To date however, the sequence of biochemical events which initiate and perpetuate the derangements in skeletal metabolism are still ill-defined. This study was undertaken to more fully delineate the defect in collagen metabolism in the chronic uremic state and to relate these changes to alterations in matrix mineralization.

\section{METHODS}

Female Holtzman rats at 6 wk of age were unilaterally nephrectomized with contralateral segmental renal infarction under light ether anesthesia. The surgery resulted in a $\frac{7}{8}$ ischemic infarction of functioning renal mass which persisted during the subsequent 2,5 , or $11 \mathrm{wk}$ period and was accompanied by an intestinal malabsorption of calcium (15). During this time, all rats were maintained on Purina laboratory chow ad lib. (Ralston Purina Co., St. Louis, Mo.) and tap water supplemented with $56 \mathrm{~mm}$ glucose and $50 \mathrm{~mm}$ sodium chloride. Concommitantly nonoperated littermates were pair-fed to the uremic rats so that both groups were of similar weight.

At the time of sacrifice all animals were bled via the abdominal aorta and the serum analyzed for calcium (16), inorganic phosphate (17), blood urea nitrogen (BUN) ${ }^{1}$

${ }^{1}$ Abbreviations used in this paper: ACP, amorphous calcium phosphate; BUN, blood urea nitrogen; $25 \mathrm{HCC}, 25-$ 
and creatinine (18). Serum samples from both 5-wk uremic and pair-fed control groups were additionally analyzed for levels of 25-hydroxycholecalciferol (25HCC) by the method of Haddad and Chyu (19). Tibiae were excised, freed of adhering connective tissue, and washed with cold isotonic saline to remove all marrow constituents. After mincing, the bone fragments were air-dried and processed as described below to determine the bone density-gradient distribution of the mineral and collagenous components.

After 4 wk of renal insufficiency, two groups of animals were given either $500 \mathrm{IU}$ of $25 \mathrm{HCC}$ or $1000 \mathrm{IU}$ of vitamin $\mathrm{D}_{\mathbf{z}}$ per day orally in cottonseed oil, for 7 days. After such therapy the rats were sacrificed as described above and the tibiae analyzed as outlined below.

The fragmented air-dried bone was reduced to a fine powder (particle size $10 \mu$ or less) in a Spex bone mixer-mill (model 5000, Spex Industries, Inc., Metuchen, N. J.), a weighed amount then layered on top of a continuous bromoform-toluene density gradient ( $\mathrm{sp} \mathrm{gr,} \mathrm{1.7-2.3).} \mathrm{After} 30 \mathrm{~min}$ of centrifugation at $10,000 \mathrm{rpm}$, measured portions were siphoned from the tube, each corresponding to a particular density fraction of 1.7-2.3 sp gr. Bone particles were distributed throughout the gradient, the less dense localized to the 1.7 to $2.0-\mathrm{sp}$ gr portions and more dense in the 2.1 to $2.3 \mathrm{sp}$ gr fractions. Since the particles were $10 \mu$ or less in size, the probability that one particle was representative of more than one osteon was slight, the diameter of an osteon being estimated as $200 \mu$ (20). That this densitygradient profile of bone reflects states of mineral-collagen maturation has been well substantiated previously by Lapiere (21).

Each density fraction was then evaporated to dryness in air and analyzed for the concentration of calcium (22) and hydroxyproline (23). Bone carbonate levels were also measured in 5-wk uremic animals and their pair-fed controls. ${ }^{2}$ The bone mineral and matrix-gradient profile was obtained in animals with uremia of 2,5 , and 11 wk duration, as well as in those who had been previously treated with either vitamin $\mathrm{D}_{3}$ or $25 \mathrm{HCC}$ for $1 \mathrm{wk}$.

To further substantiate that the density-gradient technique was representative of varying maturational states of bone collagen and mineral, bones from 5-wk uremic and pair-fed control rats were extracted with neutral salt, dilute-acid, and ethanol-ether solutions. Jackson and Bentley (24) have equated the degree of extractability of collagenous protein with its state of maturation or polymerization, and Mills and Bavetta (25) have demonstrated that this premise is valid for bone collagen and mineral. Thus the most easily extractable or neutral salt-soluble collagen represents the newly synthesized, least polymerized collagen polypeptides whereas the collagen extracted by dilute acid and ethanol-ether represents more polymerized moieties. The remaining insoluble collagen is the most mature, highly cross-linked component of the bone matrix. In these experiments the bones were progressively extracted with $0.5 \mathrm{M}$ sodium chloride, $5 \%$ trichloroacetic acid and ethanol-ether $(1: 1)$ for 1-day periods each, and the calcium and collagen hydroxyproline contents of each fraction determined as described above. The remaining insoluble bone collagen was similarly analyzed.

hydroxycholecalciferol; 25DHCC, 1,25-dihydroxycholecalciferol; PTH, parathyroid hormone.

${ }^{2}$ Kindly performed by Dr. John Termine of the National Institute of Health Dental Research, National Institutes of Health, Bethesda, Md.
TABLE I

Measurements of Calcium, Phosphate, BUN, Creatinine, and $p H$ in Rats with Chronic Renal Insufficiency*

\begin{tabular}{lrrl} 
& $\begin{array}{c}\text { Uremic } \\
\text { rats } \\
(41)\end{array}$ & $\begin{array}{c}\text { Pair-fed } \\
\text { control } \\
\text { rats } \\
(36)\end{array}$ & "P" value \\
\hline Calcium, $m g / 100 m l$ & 10.23 & 10.24 & NS \\
& \pm 0.39 & \pm 0.12 & \\
Inorganic, & 9.66 & 7.76 & $<0.005$ \\
phosphate, $m g / 100 m l$ & \pm 0.33 & +0.18 & \\
BUN, $m g / 100 m l$ & 56.00 & 24.40 & $<0.001$ \\
& \pm 2.59 & \pm 2.81 & \\
Creatinine, $m g / 100 m l$ & 1.24 & 0.56 & $<0.01$ \\
& \pm 0.05 & \pm 0.02 & \\
pH & 7.40 & 7.41 & NS \\
& \pm 0.35 & \pm 0.10 &
\end{tabular}

* The numbers in parentheses indicate the number of rats used in each experimental group. All values represent the mean $\pm 1 \mathrm{SE}$; statistical comparisons were made according to the Students' $t$ test.

Since Richelle (30) had demonstrated that fractions of increasing density corresponded to more mature bone mineral and matrix components, a series of pulse-labeling studies were also designed to distinguish impaired maturation of the bone from increased degradation. Single injections of ${ }^{45} \mathrm{Ca}(10 \mu \mathrm{Ci})$ and proline- ${ }^{8} \mathrm{H}(100 \mu \mathrm{Ci})$ were sequentially administered to rats intraperitoneally from 24 $\mathrm{hr}$ to 4 days before sacrifice, during the 5 th wk of experimental renal insufficiency. The tibiae were analyzed as previously described for the distribution of total calcium and hydroxyproline. In addition, a $20 \mu 1$ portion of each density fraction was mixed in a dioxane liquid scintillation fluor as previously described (26) and counted on a Packard Tri-Carb liquid scintillation counter (Packard Instrument Co., Downers Grove, Ill.) with external standardization.

\section{RESULTS}

The arterial concentrations of calcium, inorganic phosphate, BUN, and creatinine in the rats at the time of sacrifice as well as the $\mathrm{pH}$ are listed in Table I. Inasmuch as no significant difference was noted in these values between the 2,5 , or 11-wk uremic animals, Table $\mathrm{I}$ is a composite of all data. Although no change in serum calcium or $\mathrm{pH}$ was noted there was a significant elevation in inorganic phosphate. Whereas the histological picture of the bones obtained from 2-wk uremic animals was normal, the histological pattern of 5- and 11-wk uremic animals was characterized by an increase in osteoid tissue and osteitis fibrosa.

Despite evidence of parathyroid overactivity as demonstrated by twofold increments in gland weights and cellular hyperplasia (as well as osteitis fibrosa and osteo- 
TABLE II

Mineral and Hydroxyproline Levels in Bone Obtained from Normal and Uremic Animals*

\begin{tabular}{lcccc}
\hline & Animal weight & Calcium & $\begin{array}{l}\text { Inorganic } \\
\text { phosphate }\end{array}$ & Hydroxyproline \\
& $g$ & $m g / g$ bone & $m g / g$ bone & $m g / g$ bone \\
Pair-fed control (6) & $150.7 \pm 2.5$ & $206.09 \pm 1.15$ & $97.42 \pm 3.22$ & $6.93 \pm 0.20$ \\
2 wk uremic (6) & $149.7 \pm 12.4$ & $203.34 \pm 1.04$ & $95.77 \pm 7.66$ & $6.08 \pm 0.35$ \\
$P$ value & $(\mathrm{NS})$ & $(\mathrm{NS})$ & $(\mathrm{NS})$ & $(\mathrm{NS})$ \\
Pair-fed control (20) & $177.3 \pm 5.1$ & $201.94 \pm 2.23$ & $98.98 \pm 5.96$ & $8.01 \pm 1.02$ \\
5 wk uremic (16) & $168.9 \pm 7.8$ & $199.77 \pm 7.23$ & $101.75 \pm 6.66$ & $8.63 \pm 1.33$ \\
$P$ value & $(\mathrm{NS})$ & $(\mathrm{NS})$ & $(\mathrm{NS})$ & $(\mathrm{NS})$ \\
& & & & \\
Pair-fed control (4) & $233.5 \pm 3.9$ & $230.98 \pm 14.00$ & $97.84 \pm 0.15$ & $8.96 \pm 1.10$ \\
11 wk uremic (4) & $232.0 \pm 15.4$ & $201.05 \pm 2.19$ & $92.24 \pm 2.21$ & $7.60 \pm 0.36$ \\
$P$ value & $(\mathrm{NS})$ & $(<0.05)$ & $(<0.05)$ & $(\mathrm{NS})$ \\
\hline
\end{tabular}

* All values represent the mean $\pm 1 \mathrm{SE}$; statistical comparisons were made according to the Students' $t$ test.

The numbers in parentheses represent the numbers of animals in each experimental group.

malacia at $5 \mathrm{wk}$ ) analysis of the total calcium, phosphate, and hydroxyproline content (Table II) showed comparatively little change at this time. Bone carbonate levels were also normal in these 5 -wk uremic animals. No differences in the calcium and phosphate concentrations per gram of bone were noted until the uremia had progressed for 11 wk. Despite histological evidence of progressive increments in osteoid tissue, the bone hydroxyproline content of 11 -wk uremic animals although lower
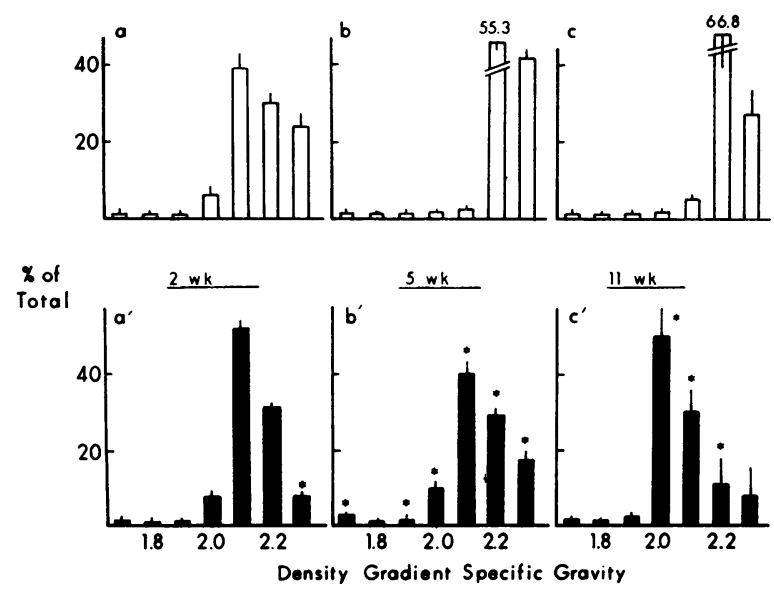

FIgURE 1 Effect of progressive renal failure on bone calcium distribution, according to the bromoform-toluene fractionation technique of Quinaux and Richelle (30). $a^{\prime}, b^{\prime}, c^{\prime}$, represent results obtained from animals with uremia of 2 , 5 , and 11 wk duration, respectively; $a, b, c$ refer to the appropriate pair-fed control population. The $\left(^{*}\right)$ in each instance signifies statistical significance between uremic and control animals with $P<0.001$ according to the Students' $t$ test. The number of animals in each group are as noted in Table II. than that of control animals was not significantly different (Table II).

The density distribution of the mineral and matrix moieties of bone obtained from the uremic animals is illustrated in Figs. 1 and 2. An analysis of the normal maturational sequence of bone revealed that with increasing age a greater proportion of the mineral and collagen matrix of bone is normally distributed in the more dense or mature fractions ( $a, b, c$, Figs. 1 and 2 ). A minimal proportion is located in the immature fractions of 1.7-2.0 sp gr. In the bones obtained from animals with uremia of 2 wk duration, there was a slight increase in the mineral and collagen of less dense, immature fractions (Figs 1 and $2 ; a$ and $a^{\prime}$ ). As the uremic state advanced, a greater proportion of the calcium and hydroxyproline was recovered in the less dense, more immature bone density fractions (Figs. 1 and $2 ; b, b^{\prime}$ and $\left.c, c^{\prime}\right)$. These findings were substantiated by the results of the salt-fractionation experiments which demonstrated a significant increase in the neutral-salt and dilute-acid soluble or immature collagen moieties in the 5 wk uremic animal (Table III).

Whether these changes in the distribution of the bone mineral and matrix were a consequence of diminished maturation and/or increased degradation of pre-existing bone could not be ascertained from an analysis of the density-gradient profiles. Consequently, a group of rats were injected sequentially with a pulse label of ${ }^{45} \mathrm{Ca}$ and proline- ${ }^{3} \mathrm{H}$ from $24 \mathrm{hr}$ to 4 days before sacrifice, during the 5th wk of renal insufficiency. As illustrated in Fig. 3, by $24 \mathrm{hr}$ most of the proline- ${ }^{3} \mathrm{H}$ and ${ }^{45} \mathrm{Ca}$ label in the bones from pair-fed control animals was located in the 2.2 and 2.3, most dense, fractions. In contrast, the distribution of radioactivity in the bones from the uremic rats 
TABLE III

Bone Mineral and Hydroxyproline Content of Neutral Salt, Acid, Alcoholic and Insoluble Collagen Fractions*

\begin{tabular}{|c|c|c|c|c|}
\hline & $\begin{array}{l}0.5 \mathrm{M} \\
\mathrm{NaCl}\end{array}$ & $\begin{array}{l}\text { Dilute } \\
\text { acid }\end{array}$ & $\begin{array}{l}\text { Ethanol- } \\
\text { ether }\end{array}$ & $\begin{array}{l}\text { Insoluble } \\
\text { collagen }\end{array}$ \\
\hline \multicolumn{5}{|l|}{ Total calcium, $m g / g$ bone } \\
\hline 5-wk uremic (13) & $2.32 \pm 0.35$ & $195.0 \pm 11.2$ & $1.49 \pm 0.84$ & $2.40 \pm 0.24$ \\
\hline Pair-fed control (12) & $\begin{array}{c}1.28 \pm 0.07 \\
(\mathrm{NS})\end{array}$ & $\begin{array}{c}193.5 \pm 34.1 \\
(\mathrm{NS})\end{array}$ & $\begin{array}{c}0.26 \pm 0.13 \\
(\mathrm{NS})\end{array}$ & $\begin{array}{c}3.41 \pm 0.48 \\
\text { (NS) }\end{array}$ \\
\hline \multicolumn{5}{|c|}{ Total OH-proline, $m g / g$ bone } \\
\hline 5 wk uremic (13) & $0.25 \pm 0.01$ & $0.27 \pm 0.02$ & $0.057 \pm 0.011$ & $5.64 \pm 1.24$ \\
\hline Pair-fed control (12) & $\begin{array}{c}0.18 \pm 0.01 \\
(<0.001)\end{array}$ & $\begin{array}{l}0.24 \pm 0.01 \\
(<0.05)\end{array}$ & $\begin{array}{c}0.028 \pm 0.002 \\
\quad(<0.001)\end{array}$ & $\begin{array}{r}6.67 \pm 0.70 \\
(<0.001)\end{array}$ \\
\hline
\end{tabular}

* According to a modification of the methods of Jackson and Bentley (24) and Mills and Bavetta (25); statistical comparisons were made according to the Students' $t$ test. All values represent the mean \pm 1 SE. The numbers in parentheses indicate the number of animals in each experimental group.

was shifted to the left, into the more immature mineral and matrix moities. 4 days after the administration of the radioactivity, a minimal proportion of the label was located in the 1.7 to 2.1-immature fractions in the control animals, whereas the concentration of tritiated or ${ }^{45} \mathrm{Ca}$ radioactivity in the density gradients of bones obtained from uremic animals was the greatest in these same low density fractions. The decreased radioactivity content of the higher density, more mature bone fractions (2.2 and 2.3) observed in this study could have resulted from a combination of decreased maturation and increased resorption, the latter reflecting the attendant increment in circulating parathyroid hormone which characterizes the chronic uremic state. The accumulation of radioactivity in the less mature 2.0 and 2.1 density fractions is consistent with the interpretation that renal failure imposes maturational defects in bone mineral and matrix metabolism.

The effect of chronic uremia on circulating $25 \mathrm{HCC}$ levels is illustrated in Table IV. Although the chronic uremic state was associated with a significant decrease in circulating $25 \mathrm{HCC}$, pretreatment with either vitamin $\mathrm{D}_{\mathbf{z}}$ or $25 \mathrm{HCC}$ in daily doses of 1000 or 500 IU respectively failed to normalize the distorted density-gradient patterns of the mineral or collagen moieties of bone described above for the untreated uremic animals (Figs. 1 and $2 ; b$ and $b^{\prime}$ ).

\section{DISCUSSION}

The studies described herein demonstrate that progressive derangements in mineral and collagen maturation of skeletal tissue attend the experimental chronic uremic state. These changes were associated with normocalcemia, hyperphosphatemia, and normal blood $\mathrm{pH}$ values. The maturational defects obtained despite normal bone content of collagen (i.e. hydroxyproline), calcium, inorganic phosphate, and carbonate, and also proved resistant to vitamin $\mathrm{D}_{3}$ or $25 \mathrm{HCC}$ therapy. To date it has not been ascertained whether the defect in mineral maturation represents an independent and coincidental abnormality or the necessary result of an intrinsic defect in collagen maturation. That the defect in mineral maturation uncovered by the density gradient (Fig. 1) and ${ }^{45} \mathrm{Ca}$ experiments (Fig. 3 ) is a true representation of bone mineral maturation has been further substantiated by measurements of "bone crystallinity" with X-ray diffraction analysis. ${ }^{2}$ The results demonstrate a significant decrease
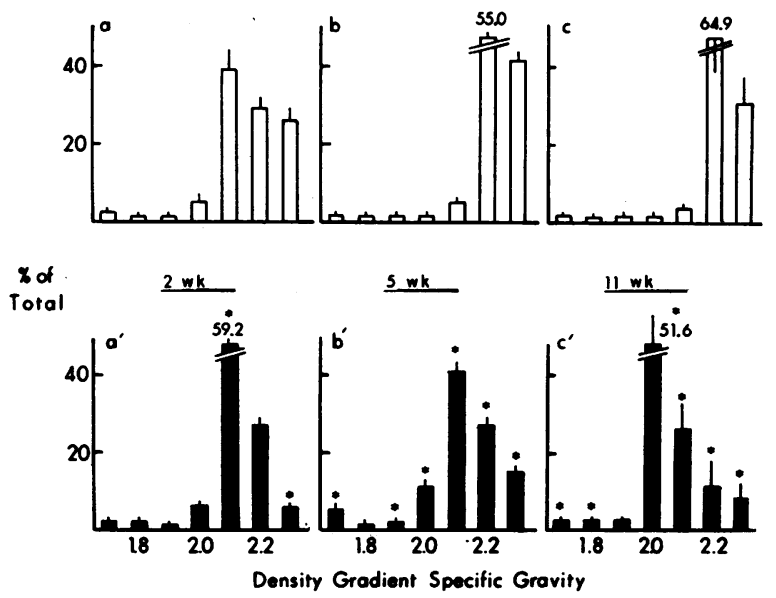

Figure 2 Effect of progressive renal failure on bone collagen (hydroxyproline) distribution, according to the bromoform-toluene fractionation technique of Quinaux and Richelle (30). $a^{\prime}, b^{\prime}, c^{\prime}$, represent results obtained from animals with uremia of 2,5 , and 11 wk duration, respectively; $a, b, c$ refer to the appropriate pair-fed control population. The $\left(^{*}\right)$ in each instance signifies statistical significance between uremic and control animals with $P<0.001$ according to the Students' $t$ test. The number of animals in each group are as noted in Table II. 


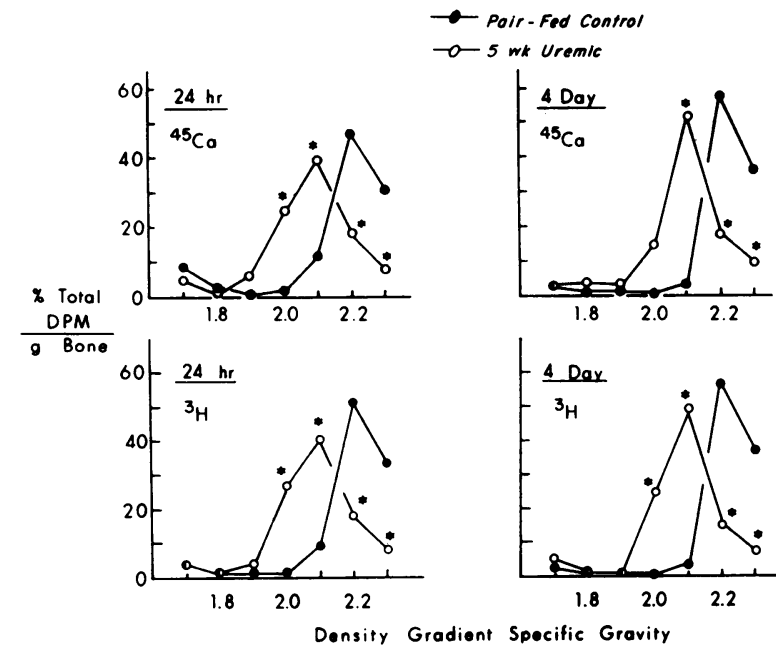

Figure $3{ }^{45} \mathrm{Ca}$ and ${ }^{3} \mathrm{H}$ distribution in bone fractions obtained by bromoform-toluene gradient fractionation, $(24 \mathrm{hr}$ and 4 days after the injection of ${ }^{45} \mathrm{CaCl}_{2}$ and proline- $\left.{ }^{3} \mathrm{H}\right)$. $(\bullet)$ refers to results obtained in control animals and ( $O$ ) refers to results obtained in animals with uremia of 5 wk duration. In each instance the $(*)$ signifies statistical significance between uremic and control animals with $P$ $<0.001$ according to the Students' $t$ test.

in mature hydroxyapatite crystals of 5-wk uremic animals $(57.7 \% \pm 1.4)$ when compared with age-matched. pair-fed controls $(64.4 \% \pm 1.6)$ as well as smaller arerage crystalline dimensions. These findings represent an increase in the immature, amorphous calcium phosphate (ACP) mineral fraction. This ACP fraction of bone mineral has been previously identified as a separate immature phase distinct from the more mature crystalline bone hydroxyapatite (27). Electron microscopic analysis (28) and in vitro physiochemical studies (29) indicate that the ACP fraction is metastable with respect to the crystalline apatite and serves as its immediate precursor. It has also been demonstrated by Quinaux and Richelle that the ACP concentration is greatest in the low density fractions illustrated in Figs. 1 and 2. decreasing progressively in more dense, mature fractions

TABLE IV

Effect of Chronic Lremia on Plasma 25-Hydroxycholecalciferol Leiels

Pair-fed control rats $n g^{\prime} m l$ (13) $7.40 \pm(0.59$

5-wk uremic rats

(11)

$$
3.46 \pm 0.70(P<0.005)
$$

The numbers in parentheses indicate the number of rats used in each experimental group); all values represent the mean \pm 1 SE; statistical comparisons were made according to the Students' $t$ test.
(30). In vitro analyses of bone obtained from acidotic patients with long-standing terminal renal failure demonstrate a decrease in both carbonate and the $\mathrm{Ca} / \mathrm{P}$ ratio and as such are consistent with an alteration in the composition of the apatite crystal $(4,5)$. The relationship between these findings and the crystalline maturational defect observed in the present study is conjectural since the changes in skeletal ACP in the uremic animals obtained despite normal blood $\mathrm{pH}$ (Table I) and bone carbonate content.

Although collagen represents only $23 \%$ of the total dry weight of bone, it comprises almost $90 \%$ of the organic matrix. The normal sequence which results in a mature collagen fibril begins with the enzymatic hydroxylation of appropriate proline and lysine residues of a polypeptide "protocollagen" precursor of collagen. Cofactors essential for this hydroxylation include oxygen, $\mathrm{Fe}^{++}$, ascorbic acid (or suitable reducing compounds), and $\alpha$-ketoglutarate (31). Since the resultant hydroxyproline accounts for $15 \%$ of the total amino acids in the collagen molecule and is not found in noncollagenous proteins, it provides a useful index of collagen content and can be equated with the collagenous protein content of skeletal tissues. Before the immature collagen molecule is extruded from the osteoblast, hydroxylsine residues may also be glycosylated with glucose and/or galactose by an enzymatic system which requires $\mathrm{Mn}^{+2}$ as a cofactor. Subsequent extracellular maturation of the immature "tropocollagen" molecule includes the formation of covalent bonds or "cross-links" between adjacent microfibrils. This "cross-linking" initially involves the conversion of the $\epsilon$-amino group of lysine or hydroxylysine of the collagen peptide to an aldehyde by a copper containing. pyridoxine-dependent enzyme, amine oxidase (32). The aldehydes subsequently form the inter- or intracollagen cross-links either by Schiff-base formation or Adol condensation (32). This phase of collagen maturation can be inhibited by lathyrtic agents such as $\beta$-aminoproprionirile $(\beta-\mathrm{APN})$, and D-penicillamine. Whereas $\beta$-APN inhibits amine oxidase activity (33), D-penicillamine acts by reacting with the aldehydes generated by the amine oxidase reaction so that they are unavailable for cross-linking (34). In both instances the induced defects in collagen metabolism result in an accumulation of the soluble, immature pool of collagenous protein and a diminution of the mature, insoluble forms.

The progressive accumulation of less dense, more immature forms of bone collagen observed in this study during the course of chronic renal failure is reminiscent of the actions of $\beta$-APN and penicillamine on collagen maturation. Uremic toxins (35) may function as inhibitors of the enzyme, amine oxidase, and/or chelators of ionic moieties essential for maximal enzymatic activity. They may also act as thiosemicarbazides which inhibit 
the formation of aldehydes in collagen and bind to preformed aldehydes $(36,37)$. In either instance the toxins would interrupt the normal progressive polymerization of the bone matrix into more mature insoluble forms. Collagen-mineral maturational defects observed in longstanding uremia may also result from alterations in bone cell carbohydrate metabolism. The hydroxylation of lysyl residues in the tropocollagen polypeptide is required to insure adequate collagen cross-linkage (32). As noted earlier, this hydroxylation step requires $\alpha$-ketoglutarate, a Kreb's cycle intermediate, and is accompanied by a stoichiometric decarboxylation of $\alpha$-ketogluturate. Although it has not yet been demonstrated that either the intracellular hydroxylations or glycosylations of the immature collagen molecule are rate-limiting, it is worth noting that preliminary observations in this laboratory demonstrate a $50 \%$ reduction in the $\mathrm{Kreb}$ 's-cycle activity of cartilage cells of chronically uremic animals (38). If the cytoplasmic concentrations of $\alpha$-ketoglutarate in uremic animals prove to be rate-limiting for the enzymatic hydroxylation of lysine, collagen deficient in hydroxylated lysine residues would be extruded from bone cells and the maturational sequence compromised. Additionally, one could link the observed derangements in bone collagen maturation to alterations in copper metabolism which reportedly attend the proteinuria of chronic renal disease (39). It has been well established in animal models that copper deficiency results in bone fragility and defects in collagen maturation (40). The defect has been ascribed to an interference with the formation of lysine-derived cross-linkages between collagen polypeptides because the amine oxidase which modifies these residues is copper dependent (41).

Vitamin $\mathrm{D}_{3}$ and its active metabolites are instrumental in affecting bone metabolism and recent observations of Canas, Brand, Neuman, and Terepka demonstrate a stimulatory effect of the vitamin on bone collagen synthesis (42). It is obvious that neither vitamin $D_{3}$ nor $25 \mathrm{HCC}$ deficiency (Table IV) could account for the maturational defect of skeletal tissue observed in this study since in separate experiments replacement therapy with either agent failed to reverse the biochenical lesion. Chronic uremia has been considered to represent a state of relative vitamin $\mathrm{D}$ deficiency because of the attendent osteomalacia, calcium malabsorption $(43,44)$. and documented defects in vitamin D metabolism (26, 45) which includes a decreased synthesis of 1,25-dihydroxycholecalciferol $(1,25 \mathrm{DHCC})$. It is possible therefore that the decrease in functioning renal mass in the uremic rats leads to a decrease in $1,25 \mathrm{DHCC}$ synthesis and that this metabolite is of fundamental importance in maintaining the integrity of bone collagen. In this regard, it is noteworthy that Oliver, Leavers, and Scott have reported that diets deficient in both vitamin $D$ and calcium lead to a decrease in the rate of synthesis of soft tissue mature collagen (46), Weber, Pons, and Kodicek cite a preferential accumulation of $1,25 \mathrm{DHCC}$ in bone (47) and Termine and Posner observed a skeletal accumulation of immature ACP mineral in the vitamin D-deficient state (27).

In this study all the uremic animals evidenced parathyroid hyperplasia and those with long-standing disease manifested the histological changes of osteitis fibrosa. It has been demonstrated that exogenous administration of parathyroid hormone ( $\mathrm{PTH})$ leads to a biphasic response in collagen metabolism. After short-term PTH treatment, collagen synthesis diminishes whereas prolonged therapy leads to an elevation in the rate of collagen synthesis (48). Flanagan and Nichols have subsequently demonstrated that a similar phenomenon obtains in patients with intermittent and continually elevated PTH secretory rates (49). Additionally, prolonged periods of excessive $\mathrm{PTH}$ secretion are attended by increased degradation of pre-existing bone $(50)$. Neither of these aforementioned phenomena would however, account for the maturational changes in bone which were documented in these animals with chronic uremia and progressive secondary hyperparathyroidism. Moreover, Bergstrom, Jacobs, Jones, and Prior have demonstrated that in the chronically uremic rat, ablation of the parathyroid glands reduced but did not eliminate the skeletal defects (51). Clearly therefore, factors other than elevated circulating $\mathrm{PTH}$ levels are operative in establishing and perpetuating the maturational derangement of mineralized tissue accompanying the chronic uremic state.

Although the biochemical changes attending the chronic uremic state may exert independent and unrelated effects on the mineral and collagen components of skeletal tissue, it is tempting to postulate that the overall changes in mineral metabolism observed in the uremic animals are actually secondary reflections of the changes in collagen metabolism. The unique physical properties of collagen distinguish it from all other proteins and as such the oriented pattern of mature skeletal collagen serves as a nidus for the deposition of mineral (52). The sites for nucleation and mineral deposition within the protein matrix of bone are geometric features intrinsic to the 640 A repeat crystal lattice of collagen (53). This "nucleation theory" is strengthened by the demonstration that maturation and increased cross-linking of newly synthesized collagen preceeds calcification $(25,54)$. It is also supported by the observation that the altered maturational sequence of bone collagen attending experimental lathrytic states is characterized by an increase in the immature ACP mineral fraction. The present studies do demonstrate that in chronic renal insufficiency decreased maturation of both matrix and mineral components of osseous tissue: (a) preceed any detectable al- 
terations in total bone mineral and collagen content; $(b)$ are not directly related to circulating levels of vitamin $\mathrm{D}_{3}$ or $25 \mathrm{HCC}$, alterations in bone carbonate or plasma $\mathrm{pH}$; and $(c)$ become progressively severe as the uremic state advances. The relationship of these findings to $1,25 \mathrm{DHCC}$ metabolism, PTH, and circulating uremic toxins is still to be determined.

\section{ACKNOWLEDGMENTS}

This study was supported in part by U. S. Public Health Service Research Grants (AM-11674 and AM-12671) and Contract (70-2219).

\section{REFERENCES}

1. Gulyassay, P. F., A. Aviram, and J. H. Peters. 1970. Evaluation of amino acid and protein requirements in chronic uremia. Arch. Intern. Med. 126: 855.

2. Stanbury, S. W. 1968. Bone disease in uremia. Am. J. Med. $44: 714$.

3. Stanbury, S. W., and G. A. Lumb. 1962. Metabolic studies of renal osteodystrophy. Medicine (Baltimore). 41: 1 .

4. Pellegrino, E. D., and R. M. Blitz. 1965. The composition of human bone in uremia. Observations on the reservoir functions of bone and demonstration of a labile fraction of bone carbonate. Medicine (Baltimore). 44: 397.

5. Kaye, M., A. J. Frueh, and M. Silverman. 1970. A study of vertebral bone powder from patients with chronic renal failure. J. Clin. Invest. 49: 442.

6. Nichols, G., Jr., B. Flanagan, J. van der Sluys Veer, J. W. Johnson, C. L. Hampers, and J. P. Merrill. 1972. Metabolic studies of bone in uremia before and after treatment. Metab. (Clin. Exp.). $21: 317$.

7. Hahn, T. J., and L. V. Avioli. 1970. Effect of chronic uremia on collagen metabolism in skin and bone. Arch. Intern. Med. 126: 882.

8. Garner, A., and J. Ball. 1966. Quantitative observations on mineralised and unmineralised bone in chronic renal azotaemia and intestinal malabsorption syndrome. $J$. Pathol. Bacteriol. 91 : 545.

9. Duursma, S. A., W. J. Visser, and L. Njio. 1972. A quantitative histological study of bone in 30 patients with renal insufficiency. Calcif. Tissue Res. 9: 216.

10. Potts, J. T., R. E. Reitz, L. J. Deftos, M. B. Kaye, J. A. Richardson, R. M. Buckle, and G. D. Aurbach. 1969. Secondary hyperparathyroidism in chronic renal disease. Arch. Intern. Med. 124 : 408.

11. Stanbury, S. W., and G. A. Lumb. 1966. Parathyroid function in chronic renal failure. A statistical survey of the plasma biochemistry in azotaemic renal osteodystrophy. Q.J. Med. $35: 1$.

12. Norman, A. W., J. F. Myrtle, R. J. Midgett, and H. G. Nowicki. 1971. 1,25 dihydroxycholecalciferol; identification of the proposed active form of vitamin $D_{3}$ in the intestine. Science (Wash. D. C.). 173: 51.

13. Gray, R., I. Boyle, and H. F. DeLuca. 1971. Vitamin D metabolism: the role of kidney tissue. Science (Wash. D. C.). $172: 1232$.

14. Lemann, J., Jr., J. R. Litzow, and E. J. Lennon. 1966. The effects of chronic acid loads in normal man: further evidence for the participation of bone mineral in the defence against chronic metabolic acidosis. $J$. Clin. Invest. 45: 1608.

15. Avioli, L. V., S. Scott, S. W. Lee, and H. F. DeLuca. 1969. Intestinal calcium absorption: nature of defect in chronic renal disease. Science (Wash. D. C.). 166: 1154.

16. Willis, J. B. 1960. The determination of calcium in blood serum by atomic absorption spectroscopy. Nature (Lond.). 186: 249.

17. Chen, P. S., T. Y. Toribara, and H. Warner. 1956. Microdetermination of phosphorus. Anal. Chem. 28: 1756.

18. AutoAnalyzer Methodology. 1965. File N-11A. Technicon Instrument Corp., Tarrytown, N. Y.

19. Haddad, J. G., and K. J. Chyu. 1971. Competitive protein-binding radioassay for 25-hydroxycholecalciferol. $J$. Clin. Endocrinol. Metab. 33: 992.

20. Herman, H., and L. Richelle. 1961. Le calcium éxchangeable de la substance minérale de l'os étudiée a l'aide du ${ }^{45} \mathrm{Ca}$. Activite compareé de fractions d'os total de densite differente. Bull. Soc. Chim. Biol. 43: 273.

21. Lapière, C. M. 1966. Remodelling of the bone matrix. In Calcified Tissues. 1965. H. Fleisch, editor. SpringerVerlag New York Inc., New York. 20.

22. Kepner, B. L., and D. M. Hercules. 1963. Fluorometric determination of calcium in blood serum. Anal. Chem. 35 : 1238.

23. Prockop, D. J., and S. Udenfriend. 1960. A specific method for the analysis of hydroxyproline in tissues and urine. Anal. Biochem. 1: 228.

24. Jackson, D. S., and J. P. Bentley. 1960. On the significance of the extractable collagens. J. Biophys. Biochem. Cytol. $7: 37$.

25. Mills, B. G., and L. A. Bavetta. 1968. Bone collagen dynamics. Clin. Orthop. Related Res. 57: 267.

26. Avioli, L. V., S. Birge, S. W. Lee, and E. Slatopolsky. 1968. The metabolic fate of vitamin $\mathrm{D}_{3}{ }^{3} \mathrm{H}$ in chronic renal failure. J. Clin. Invest. $47: 2239$.

27. Termine, J. D., and A. S. Posner. 1967. Amorphous/ crystalline interrelationships in bone mineral. Calcif. Tissue Res. $1: 8$.

28. Nylen, M. U., E. D. Eanes, and J. D. Termine. 1972. Molecular and ultrastructural studies of non-crystalline calcium phosphates. Calcif. Tissue Res. 9: 95.

29. Termine, J. D., R. A. Peckauskas, and A. S. Posner. 1970. Calcium phosphate formation in vitro. Effects of environment on amorphous-crystalline transformation. Arch. Biochem. Biophys. 140: 318.

30. Quinaux, N., and L. J. Richelle. 1967. X-ray diffraction and infrared analysis of bone specific gravity fractions in the growing rat. Isr. J. Med. Sci. 3: 677 .

31. Hutton, J. J., Jr., A. L. Tappel, and S. Udenfriend. 1967. Cofactor and substrate requirements of collagen proline hydroxylase. Arch. Biochem. Biophys. 118: 231.

32. Bornstein, P. 1970. The cross-linking of collagen and elastin and its inhibition in osteolathyrism. Is there a relation to the aging process? Am. J. Med. 49: 429.

33. Siegel, R. C., and G. R. Martin. 1970. Collagen crosslinking. Enzymatic synthesis of lysine-derived aldehydes and the production of cross-linked components. J. Biol. Chem. 245 : 1653.

34. Deshmukh, K., and M. E. Nimni. 1969. A defect in the intramolecular and intermolecular cross-linking of collagen by penicillamine. II. Functional groups involved in the interaction process. J. Biol. Chem. 244: 1787. 
35. Black, D. A. 1970. A perspective on uremic toxins. Arch. Intern. Med. 126: 906.

36. Rojkind, M., and A. M. Gutiérrez. 1969. The binding of thiosemicarbazide to collagen in vitro. Arch. Biochem. Biophys. 131 : 116.

37. Tanzer, M. L., D. Monroe, and J. Gross. 1966. Inhibition of collagen intermolecular cross-linking by thiosemicarbazide. Biochemistry. 5 : 1919.

38. Russell, J. E., and L. V. Avioli. 1971. Alteration of cartilaginous aerobic glycolysis in the chronic uremic state. Clin. Res. 19: 681. (Abstr.)

39. Cartwright, G. E., C. J. Gubler, and M. A. Wintrobe. 1954. Studies on copper metabolism. XI. Copper and iron metabolism in the nephrotic syndrome. J. Clin. Invest. 33: 685 .

40. Rucker, R. B., H. E. Parker, and J. C. Rogler. 1969. The effects of copper on collagen cross-linking. Biochem. Biophys. Res. Commun. 34: 28.

41. Miller, E. J., G. R. Martin, C. E. Mecca, and K. A. Piez. 1965. The biosynthesis of elastin cross-links. The effect of copper deficiency and a lathyrogen. J. Biol. Chem. 240: 3623.

42. Canas, F., J. S. Brand, W. F. Neuman, and A. R. Terepka. 1969. Some effects of vitamin $\mathrm{D}_{3}$ on collagen synthesis in rachitic chick cortical bone. Am. J. Physiol. 216: 1092.

43. Genuth, S. M., V. Vertes, and J. R. Leonards. 1969. Oral calcium absorption in patients with renal failure treated by chronic hemodialysis. Metab. (Clin. Exp.). $18: 124$.

44. Kaye, M., and M. Silverman. 1965. Calcium metabolism in chronic renal failure. J. Lab. Clin. Med. 66: 535.

45. Lumb, G. A., E. B. Mawer, and S. W. Stanbury. 1971. The apparent vitamin $\mathrm{D}$ resistance of chronic renal failure. A study of the physiology of vitamin D in man. Am. J. Med. 50: 421.

46. Oliver, W. M., A. G. Leaver, and P. G. Scott. 1972. The effect of deficiencies of calcium or of calcium and vitamin $D$ on the rate of oral collagen synthesis in the rat. J. Periodontal. Res. $7: 29$.

47. Weber, J. C., V. Pons, and E. Kodicek. 1971. The localization of 1,25-dihydroxycholecalciferol in bone cell nuclei of rachitic chicks. Biochem. J. 125: 147.

48. Peck, W. A., and T. A. Dirksen. 1966. The metabolism of bone tissue in vitro. Clin. Orthop. Related Res. 48: 243.

49. Flanagan, B., and G. Nichols, Jr. 1969. Bone matrix turnover and balance in vitro. I. The effects of parathyroid hormone and thyrocalcitonin. J. Clin. Invest. 48: 595.

50. Laitinen, O. 1967. Parathyroid-induced changes in collagen and calcium metabolism in vivo. Endocrinology. 80: 815 .

51. Bergstrom, W. H., E. R. Jacobs, D. B. Jones, and J. T. Prior. 1971. Influence of the parathyroid in bone lesions associated with renal insufficiency in the rat. $A m$. J. Dis. Child. 122: 601 .

52. Glimcher, M. J., and S. M. Krane. 1968. The organization and structure of bone, and the mechanism of calcification. In Treatise on Collagen. Biology of Collagen. B. S. Gould, editor. Academic Press Inc. Ltd., London. Volume 2B, 67.

53. Katz, E. P. 1969. The kinetics of mineralization in vitro. I. The nucleation properties of $640-\mathrm{A}$ collagen at 25․ Biochim. Biophys. Acta. 194: 121.

54. Uitto, J., and O. Laitinen. 1968. Relation of collagen metabolism to calcium metabolism in the bone. Acta Chem. Scand. 22 : 1039. 